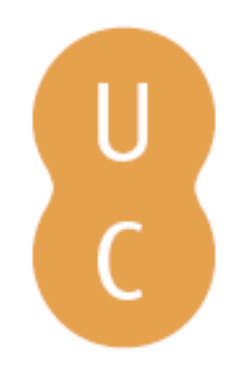

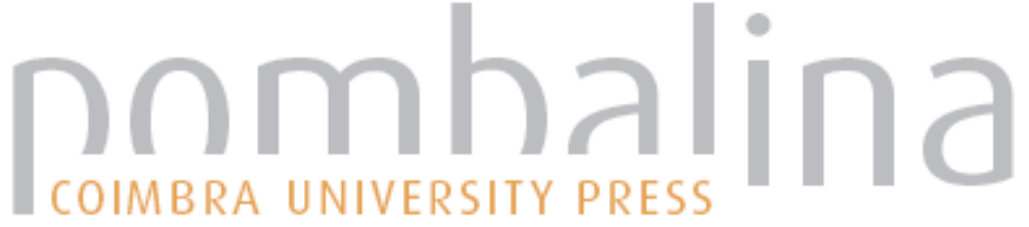

\section{Políticas públicas em educação e formação de adultos em Portugal}

Autor(es): Moio, Isabel

Publicado por: Imprensa da Universidade de Coimbra

URL

persistente: URI:http://hdl.handle.net/10316.2/41781

DOI: $\quad$ DOl:https://doi.org/10.14195/978-989-26-1362-8_8

Accessed : $\quad$ 26-Apr-2023 02:28:00

A navegação consulta e descarregamento dos títulos inseridos nas Bibliotecas Digitais UC Digitalis, UC Pombalina e UC Impactum, pressupõem a aceitação plena e sem reservas dos Termos e Condições de Uso destas Bibliotecas Digitais, disponíveis em https://digitalis.uc.pt/pt-pt/termos.

Conforme exposto nos referidos Termos e Condições de Uso, o descarregamento de títulos de acesso restrito requer uma licença válida de autorização devendo o utilizador aceder ao(s) documento(s) a partir de um endereço de IP da instituição detentora da supramencionada licença.

Ao utilizador é apenas permitido o descarregamento para uso pessoal, pelo que o emprego do(s) título(s) descarregado(s) para outro fim, designadamente comercial, carece de autorização do respetivo autor ou editor da obra.

Na medida em que todas as obras da UC Digitalis se encontram protegidas pelo Código do Direito de Autor e Direitos Conexos e demais legislação aplicável, toda a cópia, parcial ou total, deste documento, nos casos em que é legalmente admitida, deverá conter ou fazer-se acompanhar por este aviso.

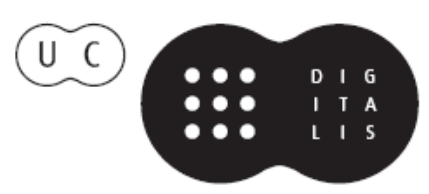




\section{PESSOAS E IDEIAS EM TRÂNSITO}

Percursos e Imaginários

RITA BASÍLIO DE SIMÕES

CLARA SERRANO

SÉRGIO NETO

JOÃO MIRANDA

(ORGS.)

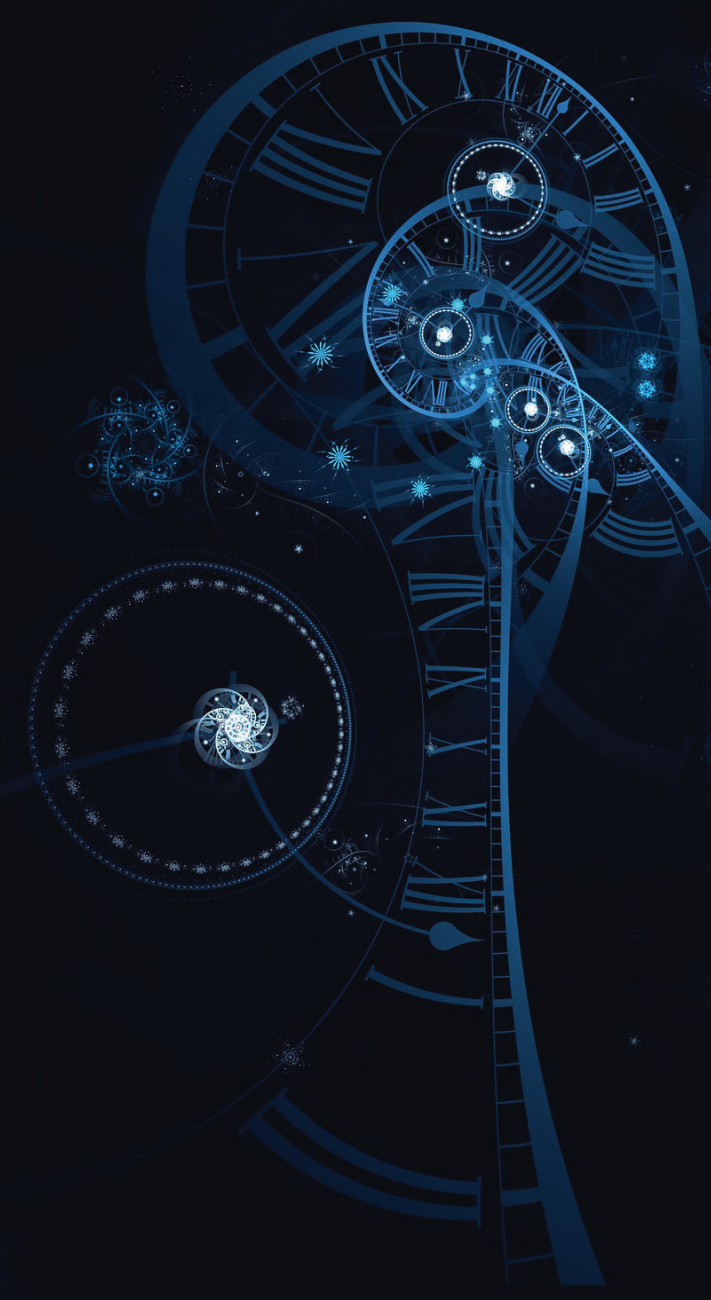

IMPRENSA DA

UNIVERSIDADE

DE COIMBRA

COIMBRA

UNIVERSITY

PRESS 


\section{POLÍTICAS PÚBLICAS EM EDUCAÇÃO \\ E FORMAÇÃO DEADULTOS EM PORTUGAL}

Isabel Moio

FPCEUC

ORCID 0000-0001-7077-4966

Resumo: Através da revisão das principais mudanças de paradigma que se repercutem na redefinição do papel do Estado na regulação da educação, são descritos os três principais modelos. Todas estas mudanças influenciam a imagem da escola, perdendo esta entidade o monopólio na certificação de saberes, passando a predominar um paradigma baseado nas competências. Analisar-se-á a redefinição do papel dos municípios portugueses na esfera educativa no sentido da sua autonomia e da construção de uma verdadeira "cidade educadora".

Palavras-chave: Estado; Governação; Aprendizagem ao longo da vida; Território; Valorização do local.

Abstract: Through the review of the major paradigmatic changes that affect the redefinition of the role of the state as to regulating education, we describe the three main models. All these changes affect the image of the school, with this entity losing the monopoly on certification and passing knowledge and with the dominance of a paradigm 
based on skills. We shall be analyzing the redefinition of the role of Portuguese Municipalities in the educational sphere in the sense of autonomy and building of a true "Educating City".

Key-words: State; Governance; Lifelong learning; Territory; Valorizing the learning locally built. 
"Não há como a força do Estado para garantir a liberdade dos seus membros"

Jean Jacques Rousseau

\section{Do modelo de Estado Educador ao conceito de governação na regulação da educação}

Desde o final do século XIX tem-se assistido a mudanças de paradigma que se repercutem na redefinição do papel do Estado na regulação e na gestão da educação, sendo possível identificar três modelos, que se filiam em lógicas e objetivos diferentes, em função do contexto sociopolítico e socioeconómico em que se circunscrevem: Estado Educador, Estado Desenvolvimentista e Estado Regulador ou Avaliador. Passa-se, assim, de uma mera função de controlo para uma missão de supervisão, refletindo-se estas mudanças na forma como se concebe a escola e se pratica a educação, apelando ao contributo de diversos atores para além dos tradicionais, num verdadeiro espírito de partilha e de rede.

1.1. Diferentes conceções de Estado: da função de controlo à de supervisão

"A evolução do sistema educativo português tem sido marcada, ao longo das últimas décadas (..), por um conjunto diversificado de reformas, muitas vezes contraditórias, que se sucedem ao ritmo da mudança dos partidos políticos que estão no governo e, muitas vezes, dos próprios ministros, independentemente das forças politicas que representam" (Barroso, 2006, p. 43). Tais reformas têm lugar no contexto político, económico e social que define os diferentes 
dos quais os múltiplos atores articulam os seus interesses e medeiam as suas diferenças, tendo em consideração que uma forma de desenvolver e assegurar estas tarefas é através da organização em rede. Esta abordagem, assumindo-se mais otimista, sublinha as limitações da ação governamental e defende que já não existe uma única entidade soberana, mas sim uma multiplicidade de atores (Lima, 2007). Os seguintes princípios coadunam-se, portanto, com os pressupostos fundamentais do modelo de Estado Regulador ou Avaliador: educação para todos, qualidade e equidade, responsabilidade, participação e negociação (Ferreira \& Seixas, 2006).

\section{2. "Da escola" para "ao longo da vida"}

Todas as mudanças registadas na evolução dos modelos de Estado e nas estratégias de regulação da educação exercem influência na forma como é concebida a imagem da escola. Mais do que uma invenção histórica, esta estrutura representa uma forma de socialização que, com a massificação do ensino, se torna hegemónica, podendo-se distinguir três mutações nos últimos anos - "Escola das Certezas", "Escola das Promessas" e "Escola das Incertezas" - que podem relacionar-se com cada um dos modelos do Estado e que anunciam a perda de monopólio por parte da escola na certificação de saberes e de conhecimentos.

\subsection{Dentro e fora da escola: do espaço institucional à valorização do não formal}

Barroso (2006, p. 43), defendendo que "a maioria da investigação e dos estudos produzidos sobre a história recente do sistema educativo português têm privilegiado a análise das reformas, dis- 
momentos históricos, não apenas dentro do terreno nacional, mas atendendo também às forças internacionais que o contaminam e que sobre ele exercem influência. A retórica do mercado surge como um instrumento legitimador das políticas educativas e as mutações sinalizadas na natureza e na configuração do Estado expressam-se, segundo Charlot (1994), em diferentes conceções, como consta no Quadro 1.

Quadro 1. Diferentes modelos de Estado, lógicas e objetivos subjacentes

\begin{tabular}{|l|c|c|c|}
\cline { 2 - 4 } \multicolumn{1}{c|}{} & Estado Educador & $\begin{array}{c}\text { Estado } \\
\text { Desenvolvimentista }\end{array}$ & $\begin{array}{c}\text { Estado } \\
\text { Regulador }\end{array}$ \\
\hline Contextualização & $\begin{array}{c}\text { Século XIX e } 1 .^{a} \text { me- } \\
\text { tade do século XX }\end{array}$ & $\begin{array}{c}\text { Décadas de } 60 \text { e } \\
70 \text { do século XX }\end{array}$ & $\begin{array}{c}\text { Desde a } \\
\text { década de } 80 \\
\text { dóculo XX }\end{array}$ \\
\hline Lógica & Político-cultural & Económica & Gestionária \\
\hline Objetivo & Integração social & $\begin{array}{c}\text { Inserção } \\
\text { profissional }\end{array}$ & $\begin{array}{c}\text { Inclusão } \\
\text { social }\end{array}$ \\
\hline
\end{tabular}

Fonte: Charlot (1994, pp. 27-44).

Charlot (2007, p. 129) afirma que já "antes da Segunda Guerra Mundial, o Estado, na sua relação com a educação, permanece um Estado Educador: pensa a educação em termos de construção da nação, paz social, inculcação de valores". Desta forma, este modelo de Estado tem subjacente uma lógica político-cultural, na medida em que o fim da educação não consiste no desenvolvimento económico nem na formação profissional, mas sim na integração social dos cidadãos.

Segundo Charlot (1994), a ação do Estado é política, filosófica, moral e cultural e não se baseia em postulados económicos. Neste 
sentido, o papel do sistema educativo passa pela socialização e pela transmissão de valores e cultura que permitem a integração dos sujeitos no todo social. Não existe espaço para o "local" nem para a diversidade porque o objetivo consiste em estabelecer uma cultura comum, ou seja, criar uma Nação e desenvolver o sentimento de pertença à mesma. No contexto português, é possível fazer corresponder a este modelo a época marcada pelo regime salazarista, tendo a expressão "Deus, Pátria, Família" sido veículo de valores que ditavam a identidade nacional.

O Estado Desenvolvimentista tem subjacente uma lógica económica - "a la logique politico-culturelle de l'État éducateur succède la logique économique d'un État "développeur»" (Charlot, 1994, p. 30). Assim, a partir dos anos 50/60 do século XX tecem-se os caminhos conducentes à construção de um Estado-Providência que se assume como Estado Desenvolvimentista. Este, de um modo claro ou disfarçado, comanda o crescimento económico e coloca a educação ao serviço do desenvolvimento. Esta política encontra um amplo consenso social devido ao facto de gerar novos empregos qualificados, bem como por satisfazer as classes médias e despertar esperança nas classes menos favorecidas (Charlot, 2007). No entanto, Gagneur e Mayen (2010) consideram que a relação entre o desenvolvimento pessoal e o desenvolvimento económico não é imediata.

Nas sociedades ocidentais, por volta dos séculos XIX e XX, "o estado tornou-se mesmo no eixo organizador do social e do individual, e durante o período áureo do Estado-Providência as questões da emancipação são quase totalmente entregues à regulação estatal" (Magalhães \& Stoer, 2006, p. 23). Para Afonso (1997) existe um relativo consenso, entre os autores portugueses que têm analisado estas questões, de que o Estado-Providência em Portugal só se acentuou após o 25 de Abril de 1974. Porém, foi acusado de ineficácia, o que conduziu ao seu declínio, traduzindo-se no reaparecimento do pensamento neoliberal e neoconservador nas arenas políticas e ideológicas. 
Na década de 80 do século XX, o Estado Desenvolvimentista deu lugar ao Estado Regulador, que remete também para lógicas económicas, mas de um modo diferente do que caracterizou os anos 60 e 70 do mesmo século; ingressa-se, a partir deste momento, na época da qualidade e da globalização (Charlot, 2007). Este autor refere que já no final da década de 60 surgiram indícios de uma crise - que se ampliou e evidenciou na década seguinte -, conducente a uma reestruturação do sistema capitalista internacional, designada por globalização e, ainda, a novos contextos, sendo de salientar: a) lógica de qualidade, eficácia e diversificação (pois face à concorrência nos mercados internos e internacionais, é preciso produzir mercadorias e serviços cada vez mais atraentes pela sua qualidade e preço, recorrendo a máquinas e a processos cada vez mais eficazes); b) recuo do Estado (uma vez que a concorrência entre empresas e a procura para mercados mais amplos induzem fenómenos de concentração económica e beneficiam multinacionais, além de que as novas lógicas impõem formas de descentralização e de territorialização).

Ao contrário dos dois modelos anteriores, o Estado Regulador ou Avaliador preocupa-se com o "local". Por isso, a lógica dominante prende-se com a gestão da diversidade e a ênfase passa a incidir na qualidade: "as lógicas da qualidade, da eficácia, da territorialização apareceram na década de 80, que foi também a década em que se desenvolveu a globalização, mas não nasceram desta" (Charlot, 2007, p.129). Ferreira e Seixas (2006) reforçam esta ideia, afirmando que o realce daqueles conceitos (bem como dos de eficiência, avaliação, racionalização e responsabilização) traduz uma nova conceção de escola e do papel do Estado relativamente aos sistemas educativos.

A política de descentralização da administração e do controlo educacionais pode assumir manifestação através de diversas estratégias, tais como: dispersão de poderes pelos vários parceiros sociais, delegação e transferência de competências para as regiões, 
desconcentração regional, autonomia institucional e introdução de lógicas com maior incidência no mercado enquanto pedra basilar.

Assim, a redefinição das funções do Estado tem implicações sob o ponto de vista educativo, na medida em que se verifica a progressiva desresponsabilização do poder central perante a pressão neoliberal (Morgado, 2007). O Estado adota, por conseguinte, uma função de supervisão e, segundo Magalhães (2001, p. 127), "a concepção política na base do modelo de supervisão estatal assume, ora implícita ora explicitamente, que a coordenação do sistema deve ser feita por leis ou por regras do tipo das da auto-regulação das instituições, opostas à regulação pela administração central". É neste cenário que se reposicionam as relações entre o Estado e a sociedade, passando-se, então, de um modelo de controlo para um modelo de supervisão.

\subsection{O binómio Estado-Mercado como regulador da Educação}

Não se pode reduzir a análise da regulação em educação a uma simples passagem ou escolha entre a regulação pelo Estado e a regulação pelo Mercado, uma vez que "não é possivel combater as "falhas" do estado com o reforço do mercado, nem as "falhas" do mercado com o reforço do estado. (...) O problema não é de «mais» ou "menos" Estado, mas de um "outro" Estado" (Barroso, 2006, p. 60). Mercado e Estado são dois termos fundamentais na definição do quadro conceptual do neoliberalismo, sendo a noção de mercado a pedra angular da tendência neoliberal, a qual se identifica com os princípios da privatização, da globalização e da livre escolha. No entanto, a relação "mais mercado / menos Estado" não tem aplicação direta no contexto educativo - optando-se pela referência a "quase-mercado" -, pois o mercado não existe em forma pura, havendo sempre um elemento ou controlo governamental sobre ele. 
Como tal, o Estado Regulador encontra-se associado a uma estratégia aparentemente paradoxal, na medida em que combina uma intensificação da intervenção do Estado na educação (neoconservadorismo) com uma mercantilização e privatização dos sistemas educativos (neoliberalismo). É possível delimitar, por isso, o contorno de duas correntes principais - neoconservadora e neoliberal -, que espelham um cenário ideológico híbrido, dando lugar a políticas aparentemente contraditórias. A reemergência do neoliberalismo apresenta-se como uma estratégia viável para a modernização da sociedade, que tem vindo a ser reforçada pela globalização e pela mundialização. Esta redefinição das funções do Estado tem implicações em termos educativos, na medida em que se verifica a progressiva desresponsabilização do poder central perante a pressão neoliberal, assumindo o Estado uma função de supervisão. Surge, então, uma nova forma de regulação estatal: "não pode deduzir-se que a presença do Estado diminuiu, mas que a regulação estatal está a assumir uma dimensão e uma latitude diferentes" (Magalhães, 2001, p. 131).

A designação de "hibridismo" contribui para acentuar o carácter plural e misto das reformas educativas, dos seus pressupostos, das suas orientações e dos seus procedimentos. Por conseguinte, essa mesma designação conduz a repensar o binómio Estado-Sociedade, emergente no século XIX, associado às conceções binárias centralização/descentralização, objetivo/subjetivo, global/ local, educação/formação. "De um modo geral, pode dizer-se que coexistem, nos diferentes países (e no mesmo país, em diferentes momentos) estratégias de regulação, desregulação, privatização, recentralização, descentralização, autonomia e controlo, mas os referenciais destas estratégias têm, por vezes, sentidos diferentes (em função dos países, das ideologias políticas, dos interesses convocados) e exercem-se em domínios distintos" (Barroso, 2006, pp. 55-56). Lamanthe (2010, p. 37) reforça esta ideia afirmando 
que "les dynamiques économiques territoriales sont diversifiées dans leur ensemble et sur un même territoire".

Para Barroso (2006, p. 61), a tentativa de superar a dicotomia entre o papel do Estado e o do Mercado "através de novas formas de governo da coisa pública e de coordenação da acção social está na origem da difusão, na ciência política, na ciência económica e nas ciências sociais em geral, de um novo conceito, de origem inglesa de "governance"".

\subsection{Governação: uma nova designação, uma nova direção}

Se durante muito tempo se considerou que o Governo estaria "acima" de tudo e que tudo coordenaria, tal perspetiva começou a revelar lacunas a partir do momento em que se verificou o acumular de políticas governamentais fracassadas (Lima, 2007). Passou, então, a ser "nítida uma certa evolução na linguagem, privilegiando-se conceitos como qualidade, eficiência e eficácia, responsabilização, clientes e contratos" (Ferreira \& Seixas, 2006, p. 270). Lima (2007) afirma que a nova filosofia de funcionamento (inspirada no ideal "menos estado, melhor estado", induzindo processos de privatização, desregulação estatal e descentralização) teve maior impacto nos EUA e no Reino Unido e essas mesmas tendências não se fizeram sentir de forma tão imediata e direta nos governos da Europa continental. Fruto destes desenvolvimentos, evidenciaram-se as interdependências entre os governos e inúmeros atores sociais e o conceito de "governação" conheceu um relevo crescente (Lima, 2007). Começa a apelar-se, portanto, à intervenção da sociedade civil, bem como ao contributo de outros agentes e atores sociais para além do Estado. No entanto, Ferreira e Seixas (2006) referem que, se por um lado a educação é considerada como um bem que diz respeito a todas as pessoas, 
por outro lado também é reforçada a necessidade de prestação de contas, responsabilização e gestão racional de todo o sistema.

Atualmente, tanto ao nível dos líderes de organizações educativas, como no que se refere à própria governação da educação, colocam-se questões relacionadas com a interação com entidades múltiplas (Lima, 2007). Como se depreende pelas mudanças no papel do Estado no que concerne à regulação da educação, este deixa de deter o monopólio de atuação. Nesta lógica, outro termo que tem concentrado a atenção de quem incide a sua reflexão sobre as transformações ocorridas nas estruturas organizacionais e nos processos de tomada de decisão, é o de rede, pois esta tem-se assumido como uma metáfora omnipresente e suscetível de descrever muitos aspetos da vida contemporânea, além de poder ser interpretada como uma estratégia alternativa de governação e de coordenação da ação social (Thompson, 2003). Parceiros sociais, autonomia, flexibilidade, diversidade, cooperação, competitividade e excelência são alguns dos termos que se interligam com as características de rede enquanto forma de conexão entre os diversos intervenientes.

Lima (2007, p. 166) afirma que "o abandono da concepção central do governo enquanto função assegurada exclusivamente pelo Estado central, em favor de uma actividade de coordenação da vida social garantida por múltiplas entidades, de forma descentralizada e até autónoma, está associado ao crescente uso do conceito de "governação", que não é tido como sinónimo de governo, mas antes utilizado para sinalizar uma mudança no significado do governo". Associada a uma abordagem e conceção de natureza mais qualitativa, esta designação vem, assim, enfatizar mais os processos do que as estruturas formais e hierarquicamente constituídas.

Além disso, a governação, sendo entendida num sentido mais lato do que o do governo, pode ser definida como o conjunto de mecanismos, de processos, de relações e de instituições através 
cutindo as suas orientações e motivações", propõe uma abordagem diferente - enfatizar o significado de tais mudanças "no quadro de uma evolução dos processos de coordenação e administração das políticas e da acção educativa" (ibidem). Na realidade, tão ou mais importante do que analisar qualquer tipo de reforma, é compreender o seu contexto e a sua direção.

Ao definir "escola", Canário (2005, p. 61) refere que "estamos em presença de uma invenção histórica, contemporânea de dupla revolução industrial e liberal (...); uma nova forma de socialização (escolar) que progressivamente viria a tornar-se hegemónica". Ainda segundo este autor, podem distinguir-se três mutações da escola nos últimos anos, devido à influência de três momentos históricos distintos e, por isso, podem ser associadas a cada um dos modelos do Estado (cf. Figura 1):

Figura 1. Paralelismo entre as diferentes imagens da Escola e os modelos do Estado

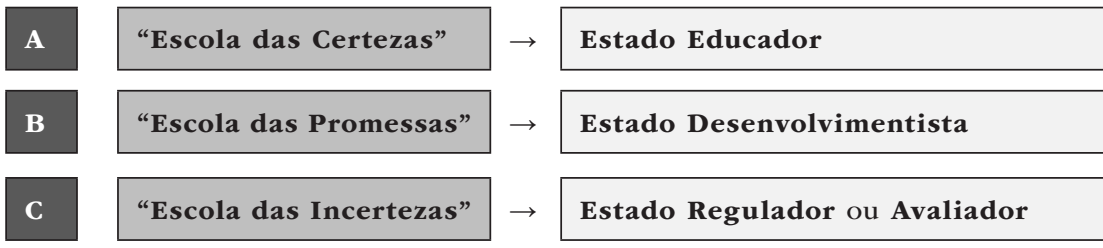

Fonte: Canário (2005).

\section{A) "Escola das Certezas" $\leftrightarrow$ Estado Educador}

A "idade de ouro" da escola situa-se no período histórico entre a Revolução Francesa e o fim da Primeira Guerra Mundial, correspondendo, por um lado, a uma fase de "harmonia entre a escola e o seu contexto externo e, por outro, a um período de harmonia 
e coerência internas entre as suas diferentes dimensões" (Canário, 2005, p. 63-64). No que se refere ao plano externo, a escola associa-se à produção de uma nova ordem política (subtração à Igreja da tutela do ensino, através da criação de um sistema nacional de escolas), social (através de uma nova construção social e de uma urbanização e proletarização aceleradas) e económica (as sociedades rurais dão lugar a sociedades industrializadas).

\section{B) "Escola das Promessas" $\leftrightarrow$ Estado Desenvolvimentista}

O período posterior à Segunda Guerra Mundial (1945-1975) é marcado pelo crescimento exponencial da oferta educativa escolar, contribuindo para isso o aumento da procura. A explosão escolar e a democratização do ensino levam à transformação da escola elitista numa escola de massas. Charlot (2007) refere que a ambição é construir a escola de nove anos, favorecendo a sua massificação, com efeitos de reprodução social, mas também de democratização. A expansão dos sistemas escolares associa-se a uma grande euforia, otimismo e promessas de desenvolvimento, mobilidade social e igualdade (de acordo com as teorias do capital humano, o investimento na educação traria benefícios em termos coletivos e individuais e esse investimento seria o responsável pelo desenvolvimento).

\section{C) "Escola das Incertezas" $\leftrightarrow$ Estado Regulador ou Avaliador}

Da euforia passa-se à deceção, na medida em que a escolarização de massas não desencadeou os efeitos desejados nem dissolveu o fosso que separava os países desenvolvidos dos subdesenvolvidos ou em vias de desenvolvimento. Assim, a previsibilidade dá lugar à incerteza, quer em relação à escola, quer em relação ao mercado de trabalho. 
O Estado nacional começa a ver recuado o seu papel devido ao processo de integração supranacional (com a constituição da União Europeia, por exemplo), ao surgimento de grupos económicos internacionais e de fenómenos de regulação transnacional, regulação nacional e microrregulação local (Barroso, 2006). Neste contexto, assiste-se a um processo de desvalorização dos diplomas, decorrente do efeito entre a expansão dos sistemas escolares e as transformações no mundo do trabalho, o que reforça a discrepância entre diplomados e os empregos correspondentes.

A dinâmica destas mudanças traz novos problemas materiais e financeiros, bem como ao nível pedagógico, pois "espalbou-se a ideia de que se abriu a escola para o povo, sem que mudasse a escola" (Charlot, 2007, p. 130).

Canário (2005) refere que as últimas décadas de estudos permitem constatar que a prática e a investigação no domínio da educação trouxeram outras modalidades educativas não escolares (o que permite analisar de um ponto de vista crítico a forma estritamente escolar e interrogá-la), em especial no que concerne ao campo da animação e da formação de adultos. Os trabalhos de Cármen Cavaco e de Mirna Montenegro (ambos de 2002), de Albertina Oliveira (2005) e de Rossana Barros (2011) são alguns exemplos de investigação sociológica que contribuem para compreender o modo como os adultos se formam a partir de uma via experiencial.

Efetivamente, a aprendizagem e o desenvolvimento dos adultos não ocorrem apenas nos espaços e nos tempos formais e institucionalizados de educação e formação; eles aprendem e desenvolvem os seus saberes e competências numa multiplicidade de situações e de contextos (formais, não formais e informais) que fazem parte das suas trajetórias de vida. As metodologias de reconhecimento, validação e certificação de competências adquiridas ao longo da vida ajustam-se a este cenário e encontram suporte, em termos teóricos, segundo Pires (2004), em alguns elementos de referência 
decorrentes das abordagens sobre a educação de adultos, nomeadamente: a aprendizagem é um processo que integra variáveis afetivas, relacionais, cognitivas, socioculturais, sensoriomotoras e experienciais; a aprendizagem e a experiência são interdependentes; os saberes e as competências adquiridas através da experiência e de contextos não formais têm valor pessoal, social e profissional, sendo necessário que, para tal, adquiram visibilidade (pois, frequentemente, são tácitos e implícitos). Para o autor (2004, p. 82), "a implementação de sistemas de reconbecimento e validação das aprendizagens que os adultos vão construindo à margem dos sistemas formais de educação/formação tem como finalidade promover a visibilidade destas aprendizagens informais, experienciais, e atribuir-lhes um "valor de uso", tanto na esfera educativa como social e profissional".

Assim, a passagem de um paradigma incidente na qualificação para um paradigma baseado na competência leva a equacionar o papel da escola sob um prisma diferente, fazendo-a perder o monopólio no que à certificação de conhecimentos diz respeito.

\subsection{A aprendizagem ao longo da vida como ferramenta na era da globalização}

$\mathrm{Na}$ sociedade do conhecimento, a partir da década de 90 do século XX, com o apanágio da globalização, segue-se um rumo que se distancia da filosofia das décadas de 60 e 70, durante as quais se acentuava a expansão e a massificação do ensino, de forma a responder à necessidade de democratização e ao aumento de qualidade que o processo de modernização e desenvolvimento da sociedade e da economia portuguesa requeriam.

Os efeitos do massivo fenómeno da globalização não pouparão para sempre o campo da aprendizagem, na medida em que também 
neste exercerá influência e terá repercussões, pelo que o investimento mais valioso é o conhecimento.

Ao passo que se impõem novas lógicas socioeconómicas e se reduz o envolvimento direto do Estado nos assuntos económicos, "diminuem as taxas de importação, abrem-se as fronteiras [a novos fluxos de bens, serviços, capital, tecnologia e ideias], estende-se a integração entre economias de vários países, integração essa que se realiza numa lógica neoliberal e que constitui a própria globalização" (Charlot, 2007, p. 131). Este é, assim, um processo gerido em função da crescente interdependência das economias e das culturas e da gradual convergência das ideologias e das políticas advogadas pelos diferentes países.

Osorio (2003) afirma que o mercado de trabalho exige mão-de-obra não só mais qualificada, como também em constante atualização, de forma a adaptar-se mais facilmente às rápidas mudanças que se desencadeiam em todos os domínios. Charlot (2007, p. 131) corrobora esta necessidade afirmando que "as novas lógicas requerem trabalhadores e consumidores mais formados $e$ qualificados, quer para produzirem mercadorias ou serviços, quer para utilizá-los. Não se trata apenas de desenvolver competências técnicas novas, mas também de aumentar o nivel de formação básica da população". Por isso, um dos efeitos da globalização consiste no aumento do nível educativo mínimo necessário para garantir a inclusão social e laboral, o que, por conseguinte, torna as sociedades mais competitivas (Bonal, 2006).

É evidente a sensação de que a universalização do ensino secundário já não é um objetivo suficiente para responder às exigências impostas pela sociedade, sendo necessário mobilizar esforços rumo à Educação e Formação ao longo (e em todos os espaços) da vida. Para Bonal (2006), esta necessidade premente de maior escolarização encontra-se relacionada com as qualificações das pessoas (competição pelos postos de trabalho pelos sujeitos 
com maior nível educativo) e com a polarização das remunerações (uma vez que a transformação dos mercados conduz ao binómio: "mais elevada qualificação - maior remuneração").

Numa primeira instância, e em sintonia com as teorias do capital humano, o investimento na educação traria retorno pessoal a longo prazo; neste sentido, a importância do investimento nesse capital decorre do seu reconhecido contributo para o crescimento económico, para o emprego e para a coesão social (Mendonça \& Carneiro, 2009). No entanto, atualmente as pessoas não podem apenas reger-se pela definição de projetos a longo prazo, pois o mercado de trabalho é uma plataforma demasiado fluida (e quantas vezes instável e precária) para transmitir a alguém a segurança e a certeza de ter um "emprego para a vida": nada pode ser dado como absoluto como no tempo em que muitas profissões se encontravam enraizadas nas famílias e eram transmitidas de geração em geração, como se se tratasse de um património seguro. A capacidade para aprender ao longo da vida é, cada vez mais, uma estratégia de combate à erosão do saber: tão ou mais importante do que simplesmente saber, é preciso ter a capacidade para transformar informação em conhecimento, conhecimento em competências e mobilizar, adaptar e ajustar as últimas em função do contexto e das circunstâncias.

Mendonça e Carneiro (2009, p. 56) afirmam que um dos objetivos inscritos no quadro da Estratégia de Lisboa é "fazer da sociedade da informação e do conbecimento uma alavanca para a coesão social e a modernização económica e tecnológica". No entanto, para que o espaço europeu se revele realmente competitivo, é necessário transformar os sistemas tradicionais de ensino (reorganizando-os e modernizando-os), devendo isso acontecer em paralelo com um novo paradigma - incidente não apenas nos conhecimentos mas, sobretudo, nas competências. A Educação e a Formação ao longo da vida são os principais desafios da nossa economia e da nossa sociedade, o que implica a adoção de políticas mais incisivas na 
melhoria do desempenho de Portugal como forma de aperfeiçoamento, extensão cultural e expansão e diversificação de vias de atualização pessoal e profissional.

A investigação e a reflexão sobre os processos não escolares de aprendizagem permitem construir uma visão teórica sobre a forma como as pessoas aprendem, sendo possível sintetizá-la em três grandes princípios (Canário, 2005): 1) a aprendizagem corresponde a um trabalho que cada sujeito realiza sobre si próprio (por isso, cada sujeito é o principal recurso para a sua aprendizagem); 2) a aprendizagem coincide com o ciclo vital (aprender é algo tão natural como respirar); 3) a aprendizagem é um processo difuso e não formal que coincide com um processo largo e multiforme de socialização.

Num contexto tão fluido como aquele em que nos movimentamos diariamente, onde o desemprego surge, sobretudo para os jovens, como uma constante ameaça (entre situações profissionais provisórias e desinserções periódicas de curta, média ou longa duração), o prolongamento e/ou o investimento nos estudos pode ser interpretado como um refúgio que camufla artificialmente os problemas do desemprego e do subemprego.

Canário (2005, p. 87) coloca a seguinte questão: "a escola tem futuro?". E a resposta pode ser assim equacionada: "o diagnóstico sobre a situação actual da escola é sombrio. (...) Não é possível adivinhar nem prever o futuro da escola, mas é possível problematizá-lo. Ou seja, é desejável agir estrategicamente, no presente, para que o futuro possa ser o resultado de uma escolha e não a consequência de um destino" (ibidem). Neste seguimento, o autor identifica três linhas orientadoras da transformação da "escola do futuro": a) pensar a escola a partir do não escolar, pois grande parte das aprendizagens significativas desenvolve-se informalmente, fora da escola; b) desalienar o trabalho escolar, tentando viabilizar caminhos que permitam transitar do enfado ao prazer; c) pensar a escola a partir de um projeto de sociedade, ou seja, a partir de algo que se deseja constituir como o devir coletivo. 


\section{Mapeamento da Educação e Formação de Adultos a partir de projetos locais}

Desde o século XIX tem-se assistido a profundas mudanças paradigmáticas e ideológicas que imprimem no Estado, enquanto decisor central, a rutura com condutas que se revelam inadequadas face às exigências. Ao delegar poderes e responsabilidades, o Estado reforça a liberdade e a autonomia de instâncias hierarquicamente inferiores, aumentando a sua amplitude decisória. Além disso, a globalização também contribui para a perda de peso da instância suprema e o recuo do seu papel justifica-se com base em três processos: nova valorização do local, abertura das fronteiras e constituição de blocos regionais (Charlot, 2007). No entanto, o Estado não deve abster-se radicalmente do exercício das suas competências, devendo "prover, dentro do interesse público, a educação, nomeadamente para os mais desfavorecidos, e garantir a igualdade de oportunidades de acesso" (Ferreira \& Seixas, 2006, p. 270).

Embora a intenção descentralizadora não seja nova, apenas recentemente tem assumido maior expressão com a redefinição do papel dos municípios portugueses na esfera educativa em aspetos que dizem respeito, por exemplo, à gestão da rede escolar e ao transporte dos alunos. Em todo este complexo processo, o desafio é, porém, muito mais abrangente do que apenas cumprir atribuições resultantes da descentralização administrativa, na medida em que é intuito que o poder local e municipal assuma capacidade na dinamização de projetos educativos locais. O papel dos poderes e das organizações locais é essencial, pois da articulação em rede e do compromisso político entre diferentes parceiros poderá resultar uma sólida eficácia de recursos com o objetivo de "desenhar planos e propósitos comuns centrados na promoção do potencial endógeno das comunidades locais" (Valente et al., 2012, p. 9). Piveteau (2010, p. 8) refere, inclusivamente, que "le territoire est aussi un espace de projet". Estes projetos, por sua vez, 
devem envolver ativamente novos atores que foram ganhando destaque sobretudo a partir da década de 80 do século XX e que concorrem, também, para a identidade de uma verdadeira cidade educadora enquanto meio educativo envolvente - conceção segundo a qual "o mapa educativo da cidade integra uma série de locais, actividades e agentes que, de forma intencional ou casual, a provê de formação" (Machado, 2005, p. 227) -, mas também como agente e conteúdo educativo. Os desafios encetados pela diluição do poder do Estado na regulação e na gestão das políticas públicas em educação levantam o de conduzir as "comunidades a assumirem-se como comunidades educadoras na qualidade de "nós" e redes de fermentação de cidades educadoras" (Valente et al., 2012, p. 9).

É essencial que o território assuma o seu papel na promoção de formas de desenvolvimento que se deseja sustentado, ou seja, um desenvolvimento que envolva todas as pessoas e integre, de forma harmoniosa, as suas várias dimensões numa perspetiva holística e hodierna de (trans)formação e num compromisso com a idiossincrasia geográfica e cultural (cf. Figura 2), favorecendo o equilíbrio e contrariando a tendência do êxodo.

Figura 2. Relação entre as dimensões do território com o processo (trans)formativo do cidadão e da comunidade.
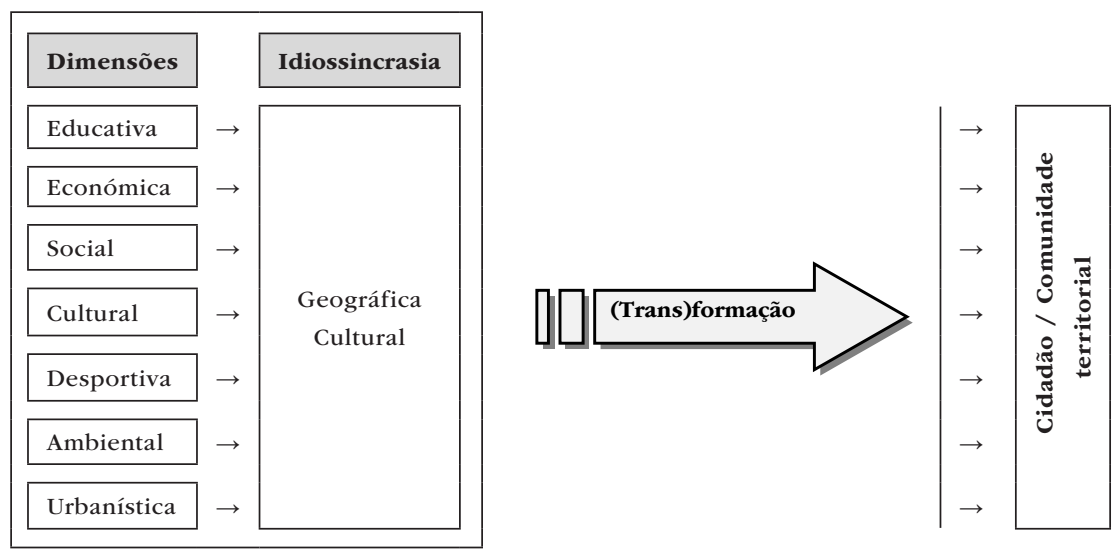
Guy Jobert, no Editorial do primeiro dos dois números temáticos que a revista Education Permanente, em 2010, dedica a este tema, defende que se deve conceber um entendimento de território como promotor de uma intencionalidade coletiva, constituindo-se como um espaço-recurso para a educação, bem como para o desenvolvimento. No seu ponto de vista, pensar o território deve significar a tentativa de unir dimensões da vida que, tradicionalmente, surgem dissociadas: a económica e a social, a individual e a coletiva, o imediato e o meio-termo, a educação e a formação de jovens e adultos e a oferta e a procura de emprego.

Planear de forma concertada o desenvolvimento integrado e sustentável, no âmbito de uma determinada comunidade territorial, pressupõe a sua articulação com um projeto de educação e de formação capaz de abranger todos os tempos e os espaços de vida, na apologia de uma aprendizagem contínua e geradora de oportunidades de participação, empenho e mobilização de diferentes atores. Corroborando-o, Piveteau (2010) afirma que os projetos de formação são essenciais na construção e coesão dos territórios, sendo entendidos não apenas como um processo de acumulação de saberes, mas também como um processo de criação de novos saberes. Contudo, não é suficiente que os atores sociais sejam obedientes e respeitadores das regras e das normas hierarquicamente impostas. Mais do que isso - e fazendo um paralelismo com o que postula Gary Hamel na sua analogia à pirâmide hierárquica das necessidades humanas para equacionar uma hierarquia das habilidades humanas no trabalho - é conveniente agir com diligência, demonstrar sentido de iniciativa e espírito criativo e atuar com paixão e envolvimento.

O desenho de políticas de intervenção educativa pressupõe que cada instituição ou programa não seja um sistema fechado e isolado, mas capaz de se interligar numa verdadeira sinergia [sýn (cooperação) + érgon (trabalho)], em que o todo é maior do que 
a soma das suas partes. Se a sinergia é geralmente maior quando a cooperação ocorre entre pessoas com diferentes habilidades (basta, para tal, pensar num modelo empresarial, na divisão do trabalho e no trabalho em equipa), o motivo mais comum que leva as pessoas a cooperar é a própria criação de sinergia.

Considerando que a sociedade adquire identidade através de um processo coletivo e negociado, com inércia e uma visão linear não se construirá um verdadeiro território educador. Urge agir segundo uma lógica de participação e emancipação das populações - traduzindo-se em impactos em toda a comunidade -, pois todos os sujeitos, independentemente do seu nível de qualificação, são potenciais atores das dinâmicas dos territórios onde vivem (Lamanthe, 2010). O desenvolvimento socioeconómico não depende apenas da educação e da qualificação, mas sobretudo da mudança das pessoas e da transformação social. Cada vez mais a política não é uma ação do Estado, mas dos agentes locais e de atores não tradicionais, o que leva a considerar que em vez de "política pública" pode falar-se em "ação pública". Constata-se uma tendência para as políticas se basearem no conhecimento especializado e os especialistas são, frequentemente, atores locais que através dos seus conhecimentos legitimam a ação. Para tal, é necessário um espaço territorial - promotor e facilitador do trabalho da sociedade civil - onde tudo isto aconteça e uma inversão do sentido das políticas educativas, fazendo-as emergir da base para o topo, numa lógica bottom-up (partindo das pessoas, do território, das experiências locais e das comunidades). Por isso, o processo de elaboração e de implementação de projetos educativos locais pretende-se amplamente participado, devendo ser a tradução da vontade de todos os agentes territoriais que se encontram envolvidos numa dinâmica de aproveitamento dos recursos disponíveis e mobilizáveis, de modo a encontrar as melhores estratégias e soluções educativas. 
Desenvolvendo-se não apenas em espaços estruturados (escolas profissionais, empresas, associações de desenvolvimento local, Instituições Particulares de Solidariedade Social, fundações, centros de formação, etc.), mas também informais e não formais, as oportunidades de aprendizagem apelam à participação alargada de diversos parceiros, como as famílias, as associações culturais e desportivas, os museus, as bibliotecas, os teatros, as salas de cinema, as exposições e as livrarias. Há lugar, assim, para uma aprendizagem que se caracteriza pela sua vertente contextualizada e experimental, simples e clara, emergente e não programada, presente, aberta e mutável.

A educação é uma das mais importantes ferramentas de valorização pessoal e de qualificação profissional, mas deve ser pensada a partir das idiossincrasias locais, valorizando o que cada cidadão conhece, o que faz, como é e como se inter-relaciona com os seus, numa sintonia com os quatro pilares da educação, abordados no Relatório para a UNESCO da Comissão Internacional sobre Educação para o Século XXI, coordenada por Jacques Delors, e publicado sob a forma de livro com o título "Educação: um tesouro a descobrir".

A evolução dos dispositivos de regulação do sistema de Educação e Formação de jovens e adultos em Portugal ocorre no sentido de convocar todos os agentes, levando-os a assumir cada vez mais responsabilidades no seu processo formativo (em função de quem são e dos seus objetivos), visando a construção de uma cidadania informada e ativa. Se até há relativamente pouco tempo o objeto de estudo preferencial da sociologia da educação era a instituição escolar, num contexto mais recente o surgimento de outros territórios e agentes educativos despoletou novas investigações. Apesar de aquela área se ter debruçado, durante muito tempo, essencialmente sobre as questões curriculares, ou seja, "sobre a análise da selecção, organização e transmissão do conhecimento escolar e seus efeitos sociais" (Loureiro, 2012, p. 129), existem alguns sinais de 
mudança, pois há casos de construção curricular que se afastam do modelo escolar, assentando a sua filosofia na metodologia do balanço de competências. Por exemplo, nos cursos de educação e formação de adultos (cursos EFA), a flexibilidade é tal que permite aos adultos realizar um itinerário diferenciado de acordo com as competências que lhes foram inicialmente reconhecidas. Assim, partindo dos seus contextos de vida e dos seus interesses, é possível desenhar diferentes caminhos formativos.

As políticas públicas adotadas reforçam a pertinência da educação e da formação como um processo coextensivo à duração da vida, ultrapassando os limites meramente escolares e apelando a todos os espaços do território com potencial educador, os quais serão tão mais eficazes na criação de oportunidades de aprendizagem quanto maior for a sua capacidade para a difundir entre todos os protagonistas. Refletir sobre o contributo da educação e da qualificação para a melhoria global das condições de vida requer um permanente questionamento dos discursos e das políticas. Se atualmente ainda se verificam acentuados défices de qualificação, dever-se-á ao facto de o Estado não ter assumido verdadeiramente o seu papel Educador? Se o investimento na educação e na formação não promoveu o desenvolvimento anunciado, significará que o Estado não cumpriu a sua função Desenvolvimentista? Neste seguimento, é legítimo perguntar ainda: face ao cenário de incerteza e precariedade que se vive, às constantes mudanças e exigências socioeconómicas e às evidentes necessidades de qualificação dos cidadãos, estará o Estado a assumir o seu papel efetivamente Regulador e a criar condições para que todos os atores sintam que têm uma palavra? Até onde chega a sua "mão invisível" e o seu "punho de ferro"?

${ }^{1}$ [A governação] "distingue-se quer da «mão invisível” de um mercado não coordenado, baseado na prossecução de interesses individuais, quer do "punho de ferro" (escondido muitas vezes em "luvas de veludo") que caracteriza a coordenação 


\section{Referências bibliográficas}

Afonso, A. (1997). Para a configuração do Estado-Providência na Educação em Portugal 1985-1995. Educação, Sociedade \& Culturas, 7, 131-156.

Barroso, J. (2006). O Estado e a Educação: a regulação transnacional, a regulação nacional e a regulação local. In João Barroso (org.), A regulação das políticas públicas de educação. Lisboa: Educa.

Bonal, X. (2006). "Reconfigurações»: Escola e Estado e Novas Definições de Mudança Social. In Magalhães, A. et al., "Reconfigurações" - Educação, Estado e Cultura numa época de globalização (pp. 91-114). Porto: Profedições.

Canário, R. (2005). O que é a Escola? Um "olhar sociológico". Porto: Porto Editora.

Charlot, B. (1994). La territorialisation des politiques éducatives: une politique nationale. In Charlot, B. (coord.), L'école et le territoire: nouveaux espaces, nouveaux enjeux. Paris: Armand Colin.

Charlot, B. (2007). Educação e Globalização: uma tentativa de colocar ordem no debate. Texto da conferência proferida na Faculdade de Psicologia e de Ciências da Educação da Universidade de Lisboa, a 14 de Junho de 2007. Sísifo. Revista de Ciências da Educação, 04, 129-136.

Ferreira, A.; Seixas, A. (2006), Dimensões ideológicas em discursos político-educativos governamentais produzidos em Portugal nas duas últimas décadas do século XX. In Estudos do Século XX, 6, 255-282.

Gagneur, C-H \& Mayen, P. (2010). Les territoires est-il une situation de développement? Education Permanente, 184, 63-77.

Lamanthe, A. (2010). Populations et qualifications, acteurs des dynamiques du territoire. Education Permanente, 184, 37-49.

Lima, J. (2007). Redes na educação: questões políticas e conceptuais. Revista Portuguesa de Educação, 20 (2), 151-181.

Loureiro, A. (2012). "Novos" territórios e agentes educativos em sociologia da educação: o caso da educação de adultos. Revista Lusófona de Educação, 20, 123-139.

Machado, J. (2005). Cidade Educadora e Coordenação Local da Educação. In J. Formosinho, A. S. Fernandes, J. Machado, \& F. I. Ferreira (Org.), Administração da Educação, Lógicas burocráticas e lógicas de mediação (pp. 225-265). Porto: Edições ASA.

Magalhães, A.; Stoer, S. (2006). «Reconfigurações»: Igualdade, Diferença e Poder. In Magalhães, A. et al.. "Reconfigurações»-Educação, Estado e Cultura numa época de globalização (pp. 141-179). Porto: Profedições.

Mendonça, M.; Carneiro, M. (2009). Análise da Iniciativa Novas Oportunidades como acção de política pública educativa (1. ${ }^{\mathrm{a}}$ ed.). Lisboa: Agência Nacional para a Qualificação, I.P.

estatal, conduzida de modo imperativo de cima para baixo" (Jessop, 2003, citado por Barroso, 2006, p. 62). 
Morgado, J. (2007). Globalização, Ensino Superior e Currículo. In Pacheco, J. et al.. Globalização e (Des)igualdades: desafios contemporâneos (pp. 61-72). Porto: Porto Editora.

Osorio, A. (2003). Educação Permanente e Educação de Adultos. Lisboa: Editorial Ariel.

Piveteau, V. (2010). Territoire-formation-développement: un triptyque à revisiter par temps changeants. Education Permanente, 185, 7-12.

Pires, A. (2004). O reconhecimento e a validação das aprendizagens dos adultos: contributos para a reflexão educativa. Trajectos - Revista de Comunicação, Cultura e Educação, 4, 81-89.

Thompson, G. (2003). Between Hierarchies \& Markets: the logic and limits of network forms of organization. Oxford: Oxford University Press.

Valente, A. et al. (2012). Aprendizagem ao longo da vida: um desafio para comunidades educadoras - uma proposta de atuação (1. ${ }^{a}$ ed.). Lisboa: Agência Nacional para a Qualificação, I.P. 